TI 2013-199/VIII

Tinbergen Institute Discussion Paper

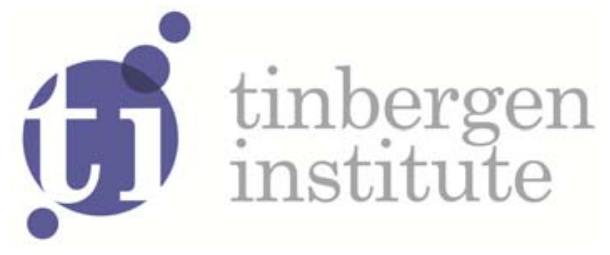

\title{
Composition Properties in the River Claims Problem
}

Erik Ansink ${ }^{1}$

Hans-Peter Weikard²

I Faculty of Economics and Business Administration, VU University Amsterdam, and Tinbergen Institute, The Netherlands;

2 Wageningen University, The Netherlands. 
Tinbergen Institute is the graduate school and research institute in economics of Erasmus University Rotterdam, the University of Amsterdam and VU University Amsterdam.

More TI discussion papers can be downloaded at http://www.tinbergen.nl

Tinbergen Institute has two locations:

Tinbergen Institute Amsterdam

Gustav Mahlerplein 117

1082 MS Amsterdam

The Netherlands

Tel.: +31(0)205251600

Tinbergen Institute Rotterdam

Burg. Oudlaan 50

3062 PA Rotterdam

The Netherlands

Tel.: +31(0)10 4088900

Fax: $+31(0) 104089031$

Duisenberg school of finance is a collaboration of the Dutch financial sector and universities, with the ambition to support innovative research and offer top quality academic education in core areas of finance.

DSF research papers can be downloaded at: http://www.dsf.nl/

Duisenberg school of finance

Gustav Mahlerplein 117

1082 MS Amsterdam

The Netherlands

Tel.: +31(0)20 5258579 


\title{
Composition properties in the river claims problem*
}

\author{
Erik Ansink ${ }^{\dagger} \quad$ Hans-Peter Weikard
}

\begin{abstract}
In a river claims problem, agents are ordered linearly, and they have both an initial water endowment as well as a claim to the total water resource. We provide characterizations of two solutions to this problem, using Composition properties which have particularly relevant interpretations for the river claims problem. Specifically, these properties relate to situations where river flow is uncertain or highly variable, possibly due to climate change impacts. The only solution that satisfies all Composition properties is the 'Harmon rule' induced by the Harmon Doctrine, which says that agents are free to use any water available on their territory, without concern for downstream impacts. The other solution that we assess is the 'No-harm rule', an extreme interpretation of the "no-harm" principle from international water law, which implies that water is allocated with priority to downstream needs. In addition to characterizing both solutions, we show their relation to priority rules and sequential sharing rules.
\end{abstract}

JEL classification: D63; C71; Q25

Keywords: river claims problem; sharing rule; Harmon Doctrine; composition axioms; water allocation

Corresponding author:

Erik Ansink

Department of Spatial Economics

VU University Amsterdam

De Boelelaan 1105

1081 HV Amsterdam

the Netherlands

Email: erik.ansink@vu.nl

Tel: +31 205981214

\footnotetext{
*We thank seminar participants of the 2013 Tinbergen Workshop on Decision Making in Water Problems at VU University Amsterdam. The first author acknowledges financial support from FP7-IDEASERC Grant No. 269788.

${ }^{\dagger}$ Department of Spatial Economics and IVM, VU University Amsterdam, and Tinbergen Institute.

${ }^{\ddagger}$ Department of Social Sciences, Wageningen University.
} 


\section{Introduction}

We provide new solutions to the river claims problem, using Composition axioms. These axioms are adapted from the literature on claims problems to the case of river sharing, where they have particularly relevant interpretations in the context of variable and uncertain river flow. Our analysis adds to the emerging literature on axiomatic approaches to river sharing (cf. Béal et al., 2013), which has two interesting features. The first is its close ties to other allocation problems with constraints on the relation between agents. Examples include hierarchies or networks (Demange, 2004; İlkılıç, 2011) and multi-period or intergenerational sharing (Arrow et al., 2004). The second feature is that the axiomatic approach can be easily put to use in negotiations on river sharing because the axioms can generally be interpreted as describing characteristics of a negotiation procedure. Such procedures can be implemented by the negotiating parties themselves, by the members of a joint river basin committee, or perhaps even by an intervening third party when conflict over water occurs (Ansink and Weikard, 2009).

Recent axiomatic studies (cf. Ambec and Sprumont, 2002; Ambec and Ehlers, 2008; Khmelnitskaya, 2010; Van den Brink et al., 2012; Béal et al., 2012) model river sharing as a cooperative game, where the axioms are imposed on the distribution of welfare to the agents. Van den Brink et al. (2013) argue that, instead, the axioms should be imposed directly on the allocation of welfare derived from water use, which allows a closer link between the axioms and actual water allocation. In this paper, we take this argument one step further and we impose axioms directly on the allocation of water. In doing so, we ignore the agents' benefit functions, which avoids some difficulties in implementing cooperative solutions for water allocation, identified by Dinar et al. (1992). The disadvantage of our direct approach is that we cannot assess solutions in terms of economic (Kaldor-Hicks) efficiency. The important advantage, however, is that it is far more realistic (cf. Dinar and Nigatu, 2013). In the vast majority of reported negotiations on river sharing, the subject of negotiation is the allocation of physical units of water, rather than the benefits derived from water use (Beach et al., 2000). Wolf (1999, page 12) argues that "In practice, economic criteria have influenced water allocations only in the exception". Furthermore, once conflicts over water are settled and property rights are mutually acknowledged, agents can decide to engage in water trade if there are unexploited welfare gains (although Ansink et al. (2012) find that the opportunities for such trade may be restricted if there are four or more agents).

Extending Ansink and Weikard (2012) to allow for settings without water scarcity, we model river sharing as a river claims problem. In such problems, agents are ordered 
linearly and each agent has both an initial water endowment and a claim to the resource. River claims problems add a linear structure to the well-known claims problem introduced by O'Neill (1982). Two differences are that in the claims problem, the agents are not ordered and that there is just one resource to be allocated to the agents (for an extensive overview of this literature, see Thomson, 2003). The three 'ingredients' of a river claims problem $\omega=\langle N, e, c\rangle$ are easily derived. The ordered set of agents $N$ is given by the countries located along the river from source to mouth. The vector of water endowments $e$ is given by inflow to the river from rainfall or tributaries. The vector of agents' claims $c$ is put forward by the agents themselves in negotiations over river water (cf. McCaffrey, 2007; Daoudy, 2008). Claims can be based on a wide range of river sharing principles, ranging from legal principles-such as the 1966 Helsinki Rules or the 1997 UN Watercourses Convention-to principles based on historical use, population, or irrigation needs (Wolf, 1999).

We propose solutions to the river claims problem based on Composition axioms, introduced by Moulin (1987) and Young (1988). These axioms pertain to the possibility that after its initial allocation, the available amount of the resource turns out to be different from what was expected. We derive four Composition axioms tailored to the setting of river sharing, using two different interpretations. One interpretation is based on variable and uncertain river flow. The other interpretation is based on a possible negotiation procedure in which upstream water is allocated before downstream water, or vice versa. We find that only one rule satisfies all four Composition axioms. This is the river sharing rule induced by the Harmon Doctrine, which says that countries are free to use any water available on their territory, without concern for downstream impacts. We provide two characterizations of this rule based on the Composition axioms. We also show the relation of the Harmon rule to both the class of sequential sharing rules (Ansink and Weikard, 2012) and the class of Priority rules (Moulin, 2000; Thomson, 2013).

In a next step we shortly assess the 'No-harm' rule, which says that countries should care about downstream impacts, and therefore, water is allocated as far downstream as required to meet downstream claims. The No-harm rule satisfies only two out of our four Composition axioms. We obtain two characterization results for the No-harm rule that are (inverse) analogues of the results obtained for the Harmon rule.

In the next section we introduce the river claims problem. In Section 3 we introduce and motivate our Composition axioms and we describe their relevance for river sharing. In Section 4 we present our characterization results and in Section 5 we conclude. 


\section{Background}

In this section we first briefly introduce the river claims problem based on Ansink and Weikard (2012). We generalize their analysis by dropping an assumption on water scarcity, as explained below. Subsequently we describe the class of sequential sharing rules that solve the river claims problem.

\subsection{The river claims problem extended}

Consider an ordered set $N=(1,2, \ldots, n)$ of agents located along a river, with agent $i$ upstream of $j$ whenever $i<j . U_{i}=\{j \in N: j<i\}$ is the set of agents upstream of $i$, and $D_{i}=\{j \in N: j>i\}$ is the set of agents downstream of $i$. On $i$ 's territory, total river flow increases by $e_{i} \geq 0$ because of e.g. rainfall. We write $e=\left(e_{1}, \ldots, e_{n}\right)$ and refer to this inflow as 'endowments'. Downstream water availability depends on upstream water allocation. Let the amount of available water on the territory of agent $i$ be denoted by $E_{i} \equiv e_{i}+\sum_{j \in U_{i}}\left(e_{j}-x_{j}\right)$, where $x=\left(x_{1}, \ldots, x_{n}\right)$ is the water allocation vector as described below. $E_{i}$ equals endowments plus run-off of unused upstream water. Each agent has an exogenous claim $c_{i} \geq 0$ to total river flow. We write $c=\left(c_{1}, \ldots, c_{n}\right)$.

We can now define the river claims problem, which concerns the allocation of water among the agents based on their claims.

Definition 1 (River claims problem). A river claims problem is a triple $\omega=\langle N, e, c\rangle$, with $N$ an ordered and finite set of agents, an endowments vector $e \in \mathbb{R}_{+}^{n}$ and a claims vector $c \in \mathbb{R}_{+}^{n}$.

Remark 1. Unlike Ansink and Weikard (2012) but consistent with e.g. Chun (1988) and Herrero et al. (1999), for the domain of general allocation problems, we do not impose water scarcity throughout the river but, instead, allow for abundance. ${ }^{1}$ The main argument for this generalization of the domain of river claims problems is their spatial and temporal setting. We illustrate both arguments using a simple example. Consider the river sharing problem $\omega=\langle N, e=(1,1,4), c=(1,3,3)\rangle$. The 'spatial' argument is that, since water flows downstream, there is scarcity upstream because agent 2 cannot satisfy his full claim with the available water of agents 1 and $2\left(e_{1}+e_{2}=2<3=c_{2}\right)$. Despite this upstream scarcity, there is no scarcity downstream, due to the large endowment of agent 3 , which exceeds his claim $\left(e_{3}=4>3=c_{3}\right)$. The uni-directionality of

\footnotetext{
${ }^{1}$ Specifically, Ansink and Weikard (2012) assume that downstream claims exceed downstream endowments at each location along the river: $c_{i}+\sum_{j \in D_{i}} c_{j} \geq e_{i}+\sum_{j \in D_{i}} e_{j} \forall i \in N$.
} 
river flow creates local scarcity, that cannot be mitigated by downstream abundance. ${ }^{2}$ The 'temporal' argument is that some of the axioms that we employ in this paper would not apply when imposing water scarcity. One of these axioms is River Composition, an invariance property that refers to situations where additional water arrives after the initially available river flow has been allocated. In the example, suppose that the initial endowment vector equals $e^{1}=(1,1,1)$ which is allocated according to some rule, for example by assigning it all to the downstream agent 3 . Now, when the remaining water $e^{2}=(0,0,3)$ arrives, we have a problem where agent 3 is satisfied, but the remaining three units of water cannot be allocated to agent 1 or 2 , due to the uni-directionality of river flow. If we would impose water scarcity, River Composition would not be applicable to this example, although the situation is very relevant in practice. Following our choice not to assume scarcity, we do impose that water can be freely disposed of.

Denote by $\Omega$ the set of river claims problems. We now define a river sharing rule for such problems.

Definition 2 (River sharing rule). A river sharing rule is a mapping $F: \Omega \rightarrow \mathbb{R}^{n}$ that assigns to every river claims problem $\omega \in \Omega$ a water allocation vector $x=\left(x_{1}, \ldots, x_{n}\right)$, $x \in \mathbb{R}_{+}^{n}$, such that
(a) $0 \leq x_{i} \leq c_{i} \forall i \in N$,
(claims-boundedness)
(b) $x_{i} \leq E_{i} \forall i \in N$, (feasibility)
(c) $\sum_{i \in N} x_{i}=\sum_{i \in N} e_{i}-\max \left\{0, \sum_{k=j}^{n}\left(e_{k}-c_{k}\right): j \in N\right\}$.
(minimum waste)

The allocation of water to agent $i$ is $F_{i}(\omega)=x_{i}$. Requirements (a)-(c) impose nonnegativity, claims-boundedness, feasibility, and minimum waste. This last requirement (c) requires additional explanation. Because we allow for the possibility of water abundance we cannot simply impose $\sum_{i \in N} x_{i}=\sum_{i \in N} e_{i}$. Instead, we correct the sum of allocated water by subtracting excess water which, if present, occurs in the downstream part of the river and is calculated by the largest $\sum_{k=j}^{n}\left(e_{k}-c_{k}\right)$. For the example in Remark 1, requirement (c) imposes that $\sum_{i \in N} x_{i}=1+1+4-\max \{0,6-7,5-6,4-3\}=5$ units of water are allocated, while 1 excess unit of water is freely disposed.

\footnotetext{
${ }^{2}$ One argument to assume water scarcity throughout the river is that 'non-scarce' problems can easily be transformed into 'scarce' problems, simply by removing the most downstream agents that do not face water scarcity. In the example, this would imply that agent 3 is removed to obtain $\omega^{\prime}=\langle N, e=(1,1), c=$ $(1,3)\rangle$.
} 


\subsection{Sequential sharing rules}

Having defined the river claims problem, one approach to solve it is by applying a sequential sharing rule. We adapt the construction and definition of such rules by Ansink and Weikard (2012) to allow for the possibility of water abundance. Denote by $c_{D_{i}} \equiv \max \left\{0, \sum_{k=i+1}^{j}\left(c_{k}-e_{k}\right): j \in D_{i}\right\}$ the downstream excess claim: the sum of claims that cannot be satisfied with downstream water, by all agents downstream of $i$. The max operator prevents negative values of the downstream excess claim. Such values could occur in absence of scarcity, as in the example in Remark 1 where we have $c_{D_{2}}=\max \{0,3-4\}=0$.

Using this definition of the downstream excess claim, a river claims problem $\omega$ can be interpreted as a sequence $\left(\omega_{1}, \ldots, \omega_{n}\right)$ of reduced river claims problems $\omega_{i}=$ $\left\langle\left\{i, D_{i}\right\}, \min \left\{E_{i}, c_{i}+c_{D_{i}}\right\},\left(c_{i}, c_{D_{i}}\right)\right\rangle$, with two agents $i$ and $D_{i}$, a claims vector $\left(c_{i}, c_{D_{i}}\right)$, and available water $\min \left\{E_{i}, c_{i}+c_{D_{i}}\right\}$. Applying free disposal of excess water, the min operator prevents the volume of water for allocation to exceed the sum of claims. A reduced river claims problem is mathematically equivalent to the two-agent version of a standard claims problem $\psi=\langle N, E, c\rangle$ so that standard rules (e.g. proportional rule, constrained equal awards rule) can be applied to any such problem.

Definition 3 (Sequential sharing rule). A sequential sharing rule based on rule $B$ for river claims problem $\omega$ is a river sharing rule $F$ that allocates to each agent the allocation provided by repeatedly applying a rule $B$ to its corresponding sequence of reduced river claims problems $\left(\omega_{1}, \ldots, \omega_{n}\right)$, so that $F_{i}(\omega)=B_{i}\left(\omega_{i}\right) \forall i \in N .^{3}$

The class of sequential sharing rules is characterized by three axioms: Only n's Excess Claim Matters, No Advantageous Downstream Merging, and Upstream Consistency (Ansink and Weikard, 2012, Proposition 1), which will be used in Section 4. Note that the construction of $c_{n}^{\prime}$ in Only n's Excess Claim Matters as well as the construction of $e_{n-1}^{\prime}$ in No Advantageous Downstream Merging is adapted to allow for the possibility of water abundance.

Axiom 1 (Only $n$ 's Excess Claim Matters). For each river claims problem $\omega=\langle N, e, c\rangle$, and each related problem $\omega^{\prime}=\left\langle N, e^{\prime}, c^{\prime}\right\rangle$ such that $e^{\prime}=\left(e_{1}, \ldots, e_{n-1}, e_{n}^{\prime}\right)$ and $c^{\prime}=\left(c_{1}, \ldots, c_{n-1}, c_{n}^{\prime}\right)$ with $e_{n}^{\prime}=0$ and $c_{n}^{\prime}=\max \left(0, c_{n}-e_{n}\right)$, we have $F_{i}(\omega)=F_{i}\left(\omega^{\prime}\right)$ for all $i \in N \backslash n$.

Axiom 2 (No Advantageous Downstream Merging). For each river claims problem $\omega=\langle N, e, c\rangle$, and each related problem $\omega^{\prime}=\left\langle N^{\prime}, e^{\prime}, c^{\prime}\right\rangle$ such that $N^{\prime}=N \backslash\{n\}$ and $e^{\prime}=$

\footnotetext{
${ }^{3}$ The definition of this class of rules shows similarities with the procedure used by Moreno-Ternero (2011) to characterize a class of rules inspired by the Talmud.
} 
$\left(e_{1}, \ldots, e_{n-2}, e_{n-1}^{\prime}\right)$ and $c^{\prime}=\left(c_{1}, \ldots, c_{n-2}, c_{n-1}^{\prime}\right)$, with $e_{n-1}^{\prime}=e_{n-1}+\min \left(c_{n}, e_{n}\right)$ and $c_{n-1}^{\prime}=$ $c_{n-1}+c_{n}$, we have $F_{i}(\omega)=F_{i}\left(\omega^{\prime}\right)$ for all $i<n-1$.

Axiom 3 (Upstream Consistency). For each river claims problem $\omega=\langle N, e, c\rangle$, each $i \in N \backslash\{1\}$, and each related problem $\omega^{\prime}=\left\langle N^{\prime}, e^{\prime}, c^{\prime}\right\rangle$ such that $N^{\prime}=N \backslash\{1\}, c^{\prime}=\left(c_{2}, \ldots, c_{n}\right)$, and $e^{\prime}=\left(e_{1}-x_{1}+e_{2}, e_{3}, \ldots, e_{n}\right)$, we have $F_{i}\left(\omega^{\prime}\right)=F_{i}(\omega)$ for all $i \in N \backslash 1$.

\section{Composition axioms}

As discussed in the Introduction, we apply two Composition axioms, introduced by Moulin (1987) and Young (1988), to the river sharing problem. Composition, also known as Lower Composition or Composition $U p$, is an invariance property that relates to the unexpected arrival of additional resources after the initially available resource has been allocated. Its dual property is Path Independence, also known as Upper Composition or Composition Down, which relates to an unexpected drop in the available resource after it has been allocated. Both axioms are particularly appealing for the case of river water sharing, as we demonstrate below.

In the following definitions of axioms, note that for two water endowment vectors $e$ and $e^{\prime}$, we write $e^{\prime}>e$ if and only if $e_{i}^{\prime} \geq e_{i} \forall i \in N$ with strict inequality for at least one agent.

Axiom 4 (River Composition). For each river claims problem $\omega=\langle N, e, c\rangle$ and each $e^{\prime}>e$ which gives the two related problems $\omega^{\prime}=\left\langle N, e^{\prime}, c\right\rangle$ and $\omega^{\prime \prime}=\left\langle N, e^{\prime}-e, c-F(\omega)\right\rangle$, we have $F\left(\omega^{\prime}\right)=F(\omega)+F\left(\omega^{\prime \prime}\right){ }^{4}$

Suppose that additional water arrives in the river after the initially available river flow has been allocated. River Composition requires that in such cases there is no difference between (i) canceling the initial allocation and reapplying the same rule to the situation with more river water; and (ii) letting agents keep their initial allocation, reducing their claims accordingly, and applying the same rule to the additional water (Moulin, 2000; Thomson, 2003).

\section{Related to River Composition is River Path Independence.}

\footnotetext{
${ }^{4}$ In the definitions by Moulin (2000) and Thomson (2003), two additional requirements are that the sum of claims exceeds the resource and that resource endowments are non-negative. In our model we allow for problems where the sum of claims does not exceed the resource, as motivated in Section 2.1. Non-negativity of endowments follows from our definition of the river claims problem in Definition 1 , which also replaces the endowment parameter by an endowment vector, consistent with the difference between claims- and river claims problems.
} 
Axiom 5 (River Path Independence). For each river claims problem $\omega=\langle N, e, c\rangle$ and each $e^{\prime}<e$ which gives the two related problems $\omega^{\prime}=\left\langle N, e^{\prime}, c\right\rangle$ and $\omega^{\prime \prime}=\left\langle N, e^{\prime}, F(\omega)\right\rangle$, we have $F\left(\omega^{\prime}\right)=F\left(\omega^{\prime \prime}\right)$.

Suppose that there is less river flow than expected so that the initial allocation of river water is infeasible. River Path Independence requires that in such cases there is no difference between (i) canceling the initial allocation and applying the same rule to the situation with less river water; and (ii) considering the initial allocation as claims on the revised water volume and applying the same rule to this new problem (Moulin, 2000; Thomson, 2003).

The River Composition and River Path Independence axioms are particularly appealing for the case of river water sharing, because of three hydrological characteristics of river flow. First, river flow is not constant; it typically displays inter-annual and seasonal variability as well as daily variation (Dettinger and Diaz, 2000; Ward et al., 2010). The variability of river flow depends on inter alia the climatological and morphological conditions of the river basin. For example, snow-dominated river basins in a temperate climate will display different run-off regimes than rain-fed rivers in an arid climate. As a result, the decision to apply a river sharing rule to the volume of annual river flow is ad hoc and may bias the outcome (e.g. when such annual sharing gives a different outcome than the sum of allocations of monthly sharing). Second, river flow is uncertain despite advanced forecasting methods (Krzysztofowicz, 2001; Montanari and Grossi, 2008). An agreed-upon river sharing rule at the start of the year may have unforeseen consequences if the realized volume of river flow deviates from the expected volume. Given hydrological uncertainties and imperfect forecasting methods, such deviations are hard to avoid. Third, this line of reasoning can be extended to encompass the potential effects of climate change on river flow and the hydrological cycle in general. In addition to increases in run-off variability and the frequency of extreme events, climate change induces changes in the mean run-off for many river basins (Milly et al., 2005; Bates et al., 2008). Such permanent changes in water availability may require rationing of water allocations (Olmstead, 2010), which is straightforward if allocation is based on a rule that satisfies River Composition, River Path Independence or, preferably, both.

As we will see in Section 4, River Composition turns out to be a very strong property. Perhaps too strong for practical use. This is one reason to study weaker versions of this axiom. A second reason is that such weaker versions are applicable when we give these axioms a slightly different interpretation, as follows. Suppose that the set of agents $N$ meets to negotiate a solution to the river claims problem. One attractive way 
of approaching the problem is to first agree on the allocation of $e_{1}$, then $e_{2}, e_{3}$, and so on, following the direction of the river downstream. The dual approach follows the same procedure in opposite direction. This interpretation of River Composition as reflecting a negotiation procedure is captured in the following two axioms.

Axiom 6 (Composition Downstream). For each river claims problem $\omega=\langle N, e, c\rangle$ with $e=\left(e_{1}, \ldots, e_{i}, 0, \ldots, 0\right)$ for some $i \in N$, and each $e^{\prime}=\left(e_{1}, \ldots, e_{i}, e_{i+1}^{\prime}, \ldots, e_{n}^{\prime}\right)>e$ which gives the two related problems $\omega^{\prime}=\left\langle N, e^{\prime}, c\right\rangle$ and $\omega^{\prime \prime}=\left\langle N, e^{\prime}-e, c-F(\omega)\right\rangle$, we have $F\left(\omega^{\prime}\right)=$ $F(\omega)+F\left(\omega^{\prime \prime}\right)$.

Axiom 7 (Composition Upstream). For each river claims problem $\omega=\langle N, e, c\rangle$ with $e=\left(0, \ldots, 0, e_{i+1}, \ldots, e_{n}\right)$ for some $i \in N$, and each $e^{\prime}=\left(e_{1}^{\prime}, \ldots, e_{i}^{\prime}, e_{i+1}, \ldots, e_{n}\right)>e$ which gives the two related problems $\omega^{\prime}=\left\langle N, e^{\prime}, c\right\rangle$ and $\omega^{\prime \prime}=\left\langle N, e^{\prime}-e, c-F(\omega)\right\rangle$, we have $F\left(\omega^{\prime}\right)=F(\omega)+F\left(\omega^{\prime \prime}\right)$.

Finally, for the characterization results in the next section, we need an additional axiom, which has a very straightforward interpretation in the river setting.

Axiom 8 (No Contribution Property). For each river claims problem $\omega=\langle N, e, c\rangle$ and for each $i \in N \backslash 1$, if $e_{i}=0$ then $F_{i}(\omega) \leq \min \left\{c_{i}, \max \left\{E_{i-1}-c_{i-1}, 0\right\}\right\}$.

The No Contribution Property states that if some agent has no water endowment, his upstream neighbour need not share any water that he can use to satisfy his own claim. In other words, if an agent does not contribute any inflow, then his allocation is secondary to his upstream neighbour's allocation. This axiom is related to the No Contribution Property on the domain of river sharing problems with transferable utility (Van den Brink et al., 2011).

\section{Characterization results}

We now proceed to the characterization results, which are summarized in Table 1 . We start with the Harmon rule and then proceed with the No-harm rule.

\subsection{The Harmon rule}

The Harmon rule implements the Harmon Doctrine in river claims problems, and is largely favorable to upstream riparians. The Harmon Doctrine refers to the principle issued in 1895 by US Attorney General Judson Harmon that countries are free to use 
any water available on their territory, without concern for downstream impacts (McCaffrey, 2007). This doctrine has been widely disputed and is currently not recognized in international water law. In fact, international water law such as the 1966 Helsinki Rules and the 1997 UN Watercourses Convention, is based primarily on the principles of "reasonable and equitable utilization" and "no significant harm to other riparians", which stand in sharp contrast to the Harmon Doctrine (Salman, 2007). Nevertheless, the Harmon Doctrine (or equivalently, the principle of Absolute Territorial Sovereignty) is often raised by upstream riparians during water disputes (Wolf, 1999).

Definition 4 (Harmon rule). The Harmon rule for a river claims problem $\omega=\langle N, e, c\rangle$ allocates water such that $F_{i}(\omega)=\min \left\{E_{i}, c_{i}\right\}$ for all $i \in N$.

An implication of the Harmon rule is that agents need not consider downstream claims in their water use decisions. Note that Van den Brink et al. (2013) study the same rule under a different name and using slightly different notation that highlights the recursive structure of allocating river water where availability depends on upstream use. We further discuss this paper at the end of this sub-section.

In Lemma 1 we show that the Harmon rule satisfies all four Composition axioms. Proofs are deferred to the Appendix.

Lemma 1. The Harmon rule satisfies River Composition, Composition Downstream, Composition Upstream, and River Path Independence.

We now turn to our characterization results. Despite its simple appeal and reasonable interpretation Composition Downstream characterizes the Harmon rule, which has been considered an extreme solution.

Proposition 1. A solution on the class of river claims problems is equal to the Harmon rule if and only if it satisfies Composition Downstream.

At first glance a characterization result based on a single axiom seems to be weak, but see Thomson (2001, Section 4.4) who dismisses such criticism as a 'counting problem' only. On a related note, several properties of the Harmon rule, such as feasibility and the minimum waste condition, are not explicitly modeled as axioms. Instead, they enter the analysis as requirements in the definition of a river sharing rule, see Definition 2.

An alternative characterization of the Harmon rule is obtained using River Path Independence: 
Proposition 2. A solution on the class of river claims problems is equal to the Harmon rule if and only if it satisfies River Path Independence and the No Contribution Property.

For the case where $e=\left(e_{1}, 0, \ldots, 0\right)$, the Harmon rule coincides with an extreme example from the class of Priority rules for claims problems due to Moulin (2000). This extreme example occurs when the set of agents is partitioned in priority classes such that each agent is in a different priority class. Then, the claims problem resembles a river claims problem, where upstream agents may be interpreted to have priority over downstream agents. The Priority rule says that the non-prioritized agent receives resources only if the claim of the prioritized agent has been fully met.

Definition 5 (Priority rule). The Priority rule for a claims problem with ordered agents $\psi=\langle N, E, c\rangle$ allocates water such that $\forall i, j \in N$ with $i<j$, if $B_{j}(\psi)>0$, then $B_{i}(\psi)=c_{i}$.

Generalizing to river claims problems-which are not constrained to the endowment vector $e=\left(e_{1}, 0, \ldots, 0\right)$ but may feature any endowment vector $e$ - the Priority rule can be used to characterize the Harmon rule as a sequential sharing rule. To see how, note that the Harmon rule can be interpreted as a sequential sharing rule, in which for each reduced river claims problem $\omega_{i}$, the rule assigns $\min \left\{E_{i}, c_{i}\right\}$ to $i$ and any remaining water to $D_{i}$. Using Definition 3, the sequential sharing rule based on the Priority rule for river claims problem $\omega$, is the river sharing rule $F$ that allocates to each agent the allocation provided by repeatedly applying the Priority rule $B$ to its corresponding sequence of reduced river claims problems $\left(\omega_{1}, \ldots, \omega_{n}\right)$, so that $F_{i}(\omega)=B_{i}\left(\omega_{i}\right) \forall i \in N$.

Proposition 3. On the class of river claims problems, the Harmon rule coincides with the sequential sharing rule based on the Priority rule.

Combining Propositions 1 and 3, and given that the Harmon rule falls within the class of sequential sharing rules, we know that Composition Downstream implies all three characterizing axioms of these rules: Only n's Excess Claim Matters, No Advantageous Downstream Merging, and Upstream Consistency. Nevertheless, none of the sequential sharing rules assessed by Ansink and Weikard (2012) (i.e. those based on the proportional rule, constrained equal awards, constrained equal losses, and the Talmud rule) satisfies Composition Downstream. Apparently, despite its simple appeal and reasonable interpretation, Composition Downstream is a very powerful property.

For completeness, we provide a second characterization of the Harmon rule, using the insight provided by Proposition 3. 
Proposition 4. A solution on the class of river claims problems is equal to the Harmon rule if and only if it satisfies Only n's Excess Claim Matters, No Advantageous Downstream Merging, Upstream Consistency, and the No Contribution Property.

Finally, and closing our analysis of the Harmon rule, it is insightful to relate our results to recent work by Van den Brink et al. (2013, Section 6), where they assess how some river sharing rules for river sharing problems with transferable utility can be applied on the domain of river claims problems. Their approach is to assume that every agent has constant marginal benefits of water use up to a satiation point, and zero marginal benefits thereafter. These satiation points are then interpreted as the agents' claims. It turns out that on the domain of river claims problems and using this approach, the downstream incremental solution, originally proposed by Ambec and Sprumont (2002), coincides with the Harmon rule.

This coincidence is quite surprising, given the emphasis that this rule puts on assignment of benefits to downstream agents on its original domain of river sharing problems (Van den Brink et al., 2007; Houba, 2008). The explanation for this coincidence is that the downstream incremental solution takes the Harmon doctrine as the basis for defining lower bounds on welfare for each (coalition of) agent(s) and then formulates an aspiration welfare level for each (coalition of) agent(s). Because there are no monetary transfers in a claims problem (or, using the above interpretation, because marginal benefits of water use are constant), the aspiration welfare does not exceed the lower bounds. Therefore, the downstream incremental solution implements the Harmon doctrine, which leads to the Harmon rule for river claims problems.

Note that Van den Brink et al. (2013) characterize the Harmon rule using three basic axioms and Independence of Downstream Claims, a property that, as suggested by its name, implies that upstream allocation is independent of the size of downstream claims. In contrast to Composition Downstream, we argue that this is not a desirable property of solutions to a river claims problem, which clearly demonstrates the two faces of the Harmon rule.

\subsection{The No-harm rule}

The No-harm rule is similar in spirit to the Harmon rule, by allocating water based on principles from international water law. The No-harm rule implements an extreme interpretation of the principle of doing "no significant harm to other riparians", and is largely favourable to downstream riparians. Joint with the principle of "reasonable and equitable utilization", it forms the basis of international water law, introduced by 
the 1966 Helsinki Rules, and incorporated by the 1997 UN Watercourses Convention. We interpret the principle in its extreme form, where it coincides with the notion of Unlimited Territorial Integrity (Salman, 2007). In this interpretation, the principle requires that no harm is done at all. This implies that water is allocated as far downstream as possible, given the claims-boundedness requirement of river sharing rules in Definition 2.

Definition 6 (No-harm rule). The No-harm rule for a river claims problem $\omega=\langle N, e, c\rangle$ allocates water such that $F_{i}(\omega)=\max \left\{0, E_{i}-c_{D_{i}}\right\}$ for all $i \in N$.

An implication of the No-harm rule is that agents only consider downstream claims in their water use decisions. Similar to the Harmon rule, Van den Brink et al. (2013, Section 6) study the No-harm rule under a different name and using slightly different notation that highlights the recursive structure of allocating river water.

The following results are related to those in Section 4.1. In Lemma 2 we show that the No-harm rule satisfies only two out of four Composition axioms.

Lemma 2 (see Lemma 1). The No-harm rule satisfies Composition Upstream and River Path Independence, but not River Composition nor Composition Downstream.

By taking the inverse of both the Priority rule and the No Contribution Property we derive characterizations for the No-harm rule that are analogue to Propositions 3 and 4.

Definition 7 (Reverse Priority rule). The Reverse Priority rule for a claims problem with ordered agents $\psi=\langle N, E, c\rangle$ allocates water such that $\forall i, j \in N$ with $i<j$, if $B_{i}(\psi)>0$, then $B_{j}(\psi)=c_{j}$.

Axiom 9 (Full Contribution Property). For each river claims problem $\omega=\langle N, e, c\rangle$ and for each $i \in N \backslash 1$, if $e_{i}=0$ then $F_{i}(\omega) \geq \min \left\{c_{i}, E_{i-1}\right\}$.

Compared to the Priority rule in Definition 5, the Reverse Priority rule just reverses the order of the agents. The rule states that, when downstream agents have priority over upstream agents, the upstream agent receives resources only if the claims of the downstream agents have been fully met. The Full Contribution Property states that if some agent has no water endowment, his upstream neighbour should provide any available water needed to satisfy the unendowed agent's claim.

Proposition 5 (see Proposition 3). On the class of river claims problems, the No-harm rule coincides with the sequential sharing rule based on the Reverse Priority rule. 
Proposition 6 (see Proposition 4). A solution on the class of river claims problems is equal to the No-harm rule if and only if it satisfies Only n's Excess Claim Matters, No Advantageous Downstream Merging, Upstream Consistency, and the Full Contribution Property.

Table 1: Axioms satisfied by the Harmon and No-harm rules. Arrows denote implication. Equal symbols in one column indicate a characterization.

\begin{tabular}{|c|c|c|}
\hline axioms $\backslash$ rules & Harmon & No-harm \\
\hline River Path Independence & yes II & yes \\
\hline River Composition & yes & no \\
\hline$\Rightarrow$ Composition Downstream & yes $\dagger$ & no \\
\hline$\Rightarrow$ Composition Upstream & yes & yes \\
\hline Only $n$ 's Excess Claim Matters & yes $\S$ & yes $\star$ \\
\hline No Advantageous Downstream Merging & yes $\S$ & yes $\star$ \\
\hline Upstream Consistency & yes $\S$ & yes $\star$ \\
\hline No Contribution Property & yes §I & no \\
\hline Full Contribution Property & no & yes $\star$ \\
\hline
\end{tabular}

The proofs of both propositions follow immediately from the proofs of Propositions 3 and 4 when replacing, respectively, the Priority rule and the No Contribution Property by their inverse. To some extent, the Reverse Priority rule and the Full Contribution Property lack the appeal of their regular counterparts in Definition 5 and Axiom 8. The main purpose of Propositions 5 and 6 is therefore to show the relation between the Harmon and No-harm rules.

Similar to the Harmon rule, Van den Brink et al. (2013) have also assessed the Noharm rule. On the domain of river claims problems, the No-harm rule coincides with the UTI incremental solution, where UTI refers to the principle of Unlimited Territorial Integrity, discussed above. They characterize the No-harm rule using three basic axioms and Independence of Upstream Claims, with an interpretation analogue to the characterization discussed in the previous sub-section on the Harmon rule.

\section{Conclusion}

Variability is a key characteristic of river flow, and constitutes the basis of uncertainty over expected water availability. The impacts of climate change on the hydrological cycle are, in many river basins, amplifying natural levels of variability. When drafting 
river sharing rules, efficiency and stability can be enhanced by taking into account such variability (Ansink and Ruijs, 2008; Ambec et al., 2013; Ansink and Houba, 2013) The applicability and desirability of the Composition axioms is evident for such rules. In our paper, the linear order provides a rigid structure to the river claims problem so that these axioms (e.g. River Composition), which are not particularly strong for claims problems (Thomson, 2003), turn out to be very strong properties in the river setting.

Our main results are that the Harmon rule is (i) the only rule that satisfies Composition Downstream, (ii) the only rule that satisfies River Path Independence and the No Contribution Property, and (iii) the only rule that satisfy all four Composition axioms. These strong results complement the recent literature that proposes to make sharing rules contingent on river flow (cf. Kilgour and Dinar, 2001; De Stefano et al., 2012). Our paper shows that even contingent rules such as proportional sharing lack some of the appeal of the Harmon rule in the context of variable river flow as formalized in the Composition axioms. This is surprising since the main argument for contingent or flexible river sharing rules is that they perform well under variability.

The reason why such rules lack the appeal of the Harmon rule in the context of variability is that many river sharing rules are based on the annual sharing of available water. Composition properties, however, deal with unexpected changes in the availability of water at any time of the year. An attractive alternative to annual sharing is therefore to share the available water based on shorter time-spans. Some river sharing treaties are already based on monthly or even weekly sharing of available water (Beach et al., 2000), thereby mitigating (or eliminating) any unexpected variability, which actually disables the Composition properties assessed in this paper. An interesting example is the Ganges treaty between India and Bangladesh. This treaty specifies a river sharing rule applied to 10-day intervals in the January 1 to May 31 dry period, contingent on river flow and based on the amount of water passing the Farakka barrage, close to the two countries' border (Tanzeema and Faisal, 2001).

Finally, the Harmon rule is a controversial rule and our paper should not be interpreted as an ignorant pledge to implement this rule. Instead, this paper should be seen in a broader line of research that aims to show the trade-offs made in choosing particular river sharing rules, using the tools of axiomatic analysis. In the current paper, we achieve this aim by focusing on variability and uncertainty of river flow and we argue that, in this context, the Harmon rule has several attractive features that were unknown, and hence unappreciated, up till now. 


\section{Appendix: Proofs}

\section{Proof of Lemma 1}

Proof. Let $F$ be the Harmon rule such that $F_{i}(\omega)=\min \left\{E_{i}, c_{i}\right\}$ for all $i \in N$, and consider a river claims problem $\omega=\langle N, e, c\rangle$. We prove the lemma for each axiom separately.

River Composition Consider $e^{\prime}>e$ such that we have the two related problems $\omega^{\prime}=$ $\left\langle N, e^{\prime}, c\right\rangle$ and $\omega^{\prime \prime}=\left\langle N, e^{\prime}-e, c-F(\omega)\right\rangle$. Start upstream with agent $i=1$. Note that we have $E_{1}^{\prime}=e_{1}^{\prime}$ and $E_{1}=e_{1} \leq e_{1}^{\prime}$ so that $E_{1}^{\prime} \geq E_{1}$.

$$
\begin{aligned}
F_{i}\left(\omega^{\prime}\right) & =\min \left\{E_{i}^{\prime}, c_{i}\right\} \\
& =\min \left\{E_{i}^{\prime}-E_{i}+E_{i}, c_{i}\right\} \\
& =\min \left\{E_{i}^{\prime}-E_{i}+\min \left\{E_{i}, c_{i}\right\}, c_{i}\right\} \\
& =\min \left\{E_{i}^{\prime}-E_{i}+\min \left\{E_{i}, c_{i}\right\}, c_{i}-\min \left\{E_{i}, c_{i}\right\}+\min \left\{E_{i}, c_{i}\right\}\right\} \\
& =\min \left\{E_{i}, c_{i}\right\}+\min \left\{E_{i}^{\prime}-E_{i}, c_{i}-\min \left\{E_{i}, c_{i}\right\}\right\} \\
& =F_{i}(\omega)+F_{i}\left(\omega^{\prime \prime}\right) .
\end{aligned}
$$

Repeat this step sequentially for the next downstream agents $i=2 \ldots n$, keeping in mind that whenever $F_{i}\left(\omega^{\prime}\right)=F_{i}(\omega)+F_{i}\left(\omega^{\prime \prime}\right)$ we have $E_{i}^{\prime} \geq E_{i}$ because $e^{\prime}>e$. This repeated argument results in $F_{i}\left(\omega^{\prime}\right)=F_{i}(\omega)+F_{i}\left(\omega^{\prime \prime}\right)$ for all $i \in N$; the Harmon rule satisfies River Composition.

Composition Downstream Because the Harmon rule satisfies River Composition, it also satisfies the weaker Composition Downstream.

Composition Upstream Because the Harmon rule satisfies River Composition, it also satisfies the weaker Composition Upstream.

River Path Independence We proceed in two steps.

1. Consider the related problem $\omega^{\prime}=\left\langle N, e^{\prime}, c\right\rangle$ with $e^{\prime}<e$. Start upstream with agent $i=1$. Note that because $E_{1}^{\prime}=e_{1}^{\prime}$ and $E_{1}=e_{1} \geq e_{1}^{\prime}$, we have $E_{1}^{\prime} \leq E_{1}$. Up to the bound where $F_{i}=c_{i}$, the Harmon rule dictates that $F_{i}$ increases linearly in $E_{i}$. As a result, $E_{1}^{\prime} \leq E_{1}$ implies $F_{1}\left(\omega^{\prime}\right) \leq F_{1}(\omega)$, with $0 \leq E_{i}^{\prime}-F_{i}\left(\omega^{\prime}\right) \leq E_{i}-F_{i}(\omega)$. Combining this last inequality with $e^{\prime}<e$, we have $E_{2}^{\prime} \leq E_{2}$, which, for similar reasons as above, implies $F_{2}\left(\omega^{\prime}\right) \leq F_{2}(\omega)$, etc. Repeat this argument sequentially 
for the next downstream agents $i=2 \ldots n$, which results in $F_{i}\left(\omega^{\prime}\right) \leq F_{i}(\omega)$ for all $i \in N$.

2. Now, consider the related problem $\omega^{\prime \prime}=\left\langle N, e^{\prime}, F(\omega)\right\rangle$. Start upstream with agent $i=1$. There are two possibilities.

(a) If $F_{i}\left(\omega^{\prime}\right)=\min \left\{E_{i}^{\prime}, c_{i}\right\}=c_{i}$, then by claims boundedness and $F_{i}\left(\omega^{\prime}\right) \leq F_{i}(\omega)$ for all $i \in N$ (the result of Step 1), we have $F_{i}(\omega)=c_{i}$ and therefore $F_{i}\left(\omega^{\prime \prime}\right)=$ $\min \left\{E_{i}^{\prime}, F_{i}(\omega)\right\}=c_{i}=F_{i}\left(\omega^{\prime}\right)$.

(b) If $F_{i}\left(\omega^{\prime}\right)=\min \left\{E_{i}^{\prime}, c_{i}\right\}=E_{i}^{\prime}$, then by $F_{i}\left(\omega^{\prime}\right) \leq F_{i}(\omega)$ for all $i \in N$ (the result of Step 1), we have $F_{i}(\omega)>E_{i}^{\prime}$ and therefore $F_{i}\left(\omega^{\prime \prime}\right)=\min \left\{E_{i}^{\prime}, F_{i}(\omega)\right\}=E_{i}^{\prime}=$ $F_{i}\left(\omega^{\prime}\right)$.

Repeat this step sequentially for the next downstream agents $i=2 \ldots n$. This repeated argument results in $F\left(\omega^{\prime}\right)=F\left(\omega^{\prime \prime}\right)$; the Harmon rule satisfies River Path Independence.

\section{Proof of Proposition 1}

Proof. By Lemma 1, the Harmon rule satisfies Composition Downstream. Therefore it is sufficient to prove that this axiom implies a unique solution, equal to the Harmon rule. Let $F$ be a river sharing rule that satisfies Composition Downstream. Consider a river claims problem $\omega=\langle N, e, c\rangle$ with $e=\left(e_{1}, \ldots, e_{i}, 0, \ldots, 0\right)$ for some $i \in N$. We proceed in two steps.

1. Consider the two related problems

$$
\begin{aligned}
\omega^{\prime} & =\left\langle N,\left(e_{1}, \ldots, e_{i}, e_{i+1}^{\prime}, \ldots, e_{n}^{\prime}\right), c\right\rangle \text { and } \\
\omega^{\prime \prime} & =\left\langle N,\left(0, \ldots, 0, e_{i+1}^{\prime}, \ldots, e_{n}^{\prime}\right), c-F(\omega)\right\rangle .
\end{aligned}
$$

By the feasibility requirement of river sharing rules in Definition $2, F_{j}\left(\omega^{\prime \prime}\right)=0$ for all $j \leq i$ and for any $i \in N$. Apply Composition Downstream to obtain $F_{j}\left(\omega^{\prime}\right)=F_{j}(\omega)$ for all $j \leq i$ and for any $i \in N$.

2. Consider agent $j$ in problem $\omega^{\prime}$ and suppose $c_{D_{j}}=0$, implying that downstream agents have excess water and any water not used by agent $j$ is disposed of. By the minimum waste requirement of river sharing rules in Definition 2, we have $F_{j}\left(\omega^{\prime}\right)=\min \left\{E_{j}^{\prime}, c_{j}\right\}$. By Step 1, we have the same allocation to agent $j$ in the related problem $\omega$ for the case where $c_{D_{j}}>0$ for all $j \leq i$. Formally, $F_{j}(\omega)=F_{j}\left(\omega^{\prime}\right)=$ $\min \left\{E_{j}, c_{j}\right\}$ for any $j \leq i$ and for any $i \in N$. 
Because Step 2 holds for all agents, we obtain the Harmon rule: $F_{i}(\omega)=\min \left\{E_{i}, c_{i}\right\}$ for all $i \in N$.

\section{Proof of Proposition 2}

Proof. We know from Lemma 1 that the Harmon rule satisfies River Path Independence. In addition, it is straightforward to verify that the Harmon rule satisfies the No Contribution Property. It remains to be proven that if a river sharing rule $F$ satisfies River Path Independence and the No Contribution Property, then it is the Harmon rule. We prove the proposition by (recursive) construction in two steps.

1. Consider problem $\omega=\langle N, e, c\rangle$ and the two related problems $\omega^{\prime}=\left\langle N,\left(e_{1}, 0, \ldots, 0\right), c\right\rangle$ and $\omega^{\prime \prime}=\left\langle N,\left(e_{1}, 0, \ldots, 0\right), F(\omega)\right\rangle$. Because of claims boundedness and the No Contribution Property we have $F_{1}\left(\omega^{\prime}\right)=\min \left(c_{1}, e_{1}\right)$ and $F_{1}\left(\omega^{\prime \prime}\right)=\min \left(F_{1}(\omega), e_{1}\right)$. River Path Independence requires $F_{1}\left(\omega^{\prime \prime}\right)=F_{1}\left(\omega^{\prime}\right)$. Hence if $c_{1} \leq e_{1}$, then $F_{1}(\omega)=c_{1}$ and if $e_{1} \leq c_{1}$, then $F_{1}(\omega)=e_{1}$; in problem $\omega$ agent 1 gets what the Harmon rule requires.

2. Next, consider problem $\omega=\langle N, e, c\rangle$ and the two related problems $\omega^{\prime}=\left\langle N,\left(e_{1}, e_{2}, 0, \ldots, 0\right), c\right\rangle$ and $\omega^{\prime \prime}=\left\langle N,\left(e_{1}, e_{2}, 0, \ldots, 0\right), F(\omega)\right\rangle$. Because of claims boundedness and the $N o$ Contribution Property we have $F_{2}\left(\omega^{\prime}\right)=\min \left(c_{2}, E_{2}\right)$ and $F_{2}\left(\omega^{\prime \prime}\right)=\min \left(F_{2}(\omega), E_{2}\right)$ with $E_{2}$ given by step 1 as $e_{1}+e_{2}-F_{1}(\omega)$. River Path Independence requires $F_{2}\left(\omega^{\prime \prime}\right)=F_{2}\left(\omega^{\prime}\right)$. Hence if $c_{2} \leq E_{2}$, then $F_{2}(\omega)=c_{2}$ and if $E_{2} \leq c_{2}$, then $F_{2}(\omega)=E_{2}$; in problem $\omega$ agent 2 gets what the Harmon rule requires.

Repeat this step sequentially for the next downstream agents $i=2 \ldots n$ and we obtain the Harmon rule: $F_{i}(\omega)=\min \left\{E_{i}, c_{i}\right\}$ for all $i \in N$.

\section{Proof of Proposition 3}

Proof. Consider river claims problem $\omega=\langle N, e, c\rangle$ and its sequence $\left(\omega_{1}, \ldots, \omega_{n}\right)$ of reduced river claims problems $\omega_{i}=\left\langle\left\{i, D_{i}\right\}, E_{i},\left(c_{i}, c_{D_{i}}\right)\right\rangle$. We apply $F$, the sequential sharing rule based on the Priority rule. Consider the first of these reduced problems, $\omega_{1}=\left\langle\left\{1, D_{1}\right\}, E_{1},\left(c_{1}, c_{D_{1}}\right)\right\rangle$, where $E_{1}=e_{1}$. Applying the Priority rule $B$ to $\omega_{1}$, we obtain

$$
\begin{array}{lll}
\text { if } c_{1} \leq E_{1}: & B_{1}\left(\omega_{1}\right)=c_{1} & B_{D_{1}}\left(\omega_{1}\right)=E_{1}-c_{1} \\
\text { if } c_{1}>E_{1}: & B_{1}\left(\omega_{1}\right)=E_{1} & B_{D_{1}}\left(\omega_{1}\right)=0 .
\end{array}
$$


Therefore, $F_{1}(\omega)=B_{1}\left(\omega_{1}\right)=\min \left\{E_{1}, c_{1}\right\}$. Proceed sequentially to the next reduced problems $\left(\omega_{2}, \ldots, \omega_{n}\right)$, and repeatedly apply the Priority rule $B$ to $\omega_{i}$. We obtain for each problem

$$
\begin{array}{lll}
\text { if } c_{i} \leq E_{i}: & B_{i}\left(\omega_{1}\right)=c_{i} & B_{D_{i}}\left(\omega_{1}\right)=E_{i}-c_{i} \\
\text { if } c_{i}>E_{i}: & B_{i}\left(\omega_{1}\right)=E_{i} & B_{D_{i}}\left(\omega_{1}\right)=0 .
\end{array}
$$

Therefore, we obtain the Harmon rule: $F_{i}(\omega)=\min \left\{E_{i}, c_{i}\right\}$ for all $i \in N$.

\section{Proof of Proposition 4}

Proof. By Proposition 3, because the Harmon rule falls within the class of sequential sharing rules, we know that the Harmon rule satisfies Only n's Excess Claim Matters, No Advantageous Downstream Merging, and Upstream Consistency. In addition, it is straightforward to verify that the Harmon rule satisfies the No Contribution Property. Next, we prove that any river sharing rule $F$ that satisfies the four axioms determines a unique solution, equal to the Harmon rule. We follow the same steps as used in the second part of the proof of Proposition 1 by Ansink and Weikard (2012). Consider river claims problem $\omega=\langle N, e, c\rangle$. We first show in three steps that $F_{1}(\omega)=\min \left\{E_{1}, c_{1}\right\}$.

1. Apply No Advantageous Downstream Merging to agent 1 so that we have $F_{1}(\omega)=$ $F_{1}\left(\left\langle\left\{1, D_{1}\right\},\left(e_{1}, \sum_{j \in D_{1}} e_{j}\right),\left(c_{1}, \sum_{j \in D_{1}} c_{j}\right)\right\rangle\right)$.

2. From here, apply Only n's Excess Claim Matters repeatedly to obtain $F_{1}(\omega)=$ $F_{1}\left(\left\langle\left\{1, D_{1}\right\},\left(e_{1}, 0\right),\left(c_{1}, \sum_{j \in D_{1}}\left(c_{j}-e_{j}\right)\right\rangle\right)\right.$.

3. From here, apply the No Contribution Property to obtain $F_{1}(\omega)=\min \left\{E_{1}, c_{1}\right\}$.

We now show in four steps that $F_{2}(\omega)=\min \left\{E_{2}, c_{2}\right\}$.

1. Apply No Advantageous Downstream Merging to agent 2 so that we have $F_{2}(\omega)=$ $F_{2}\left(\left\langle\left\{1,2, D_{2}\right\},\left(e_{1}, e_{2}, \sum_{j \in D_{2}} e_{j}\right),\left(c_{1}, \sum_{j \in D_{2}} c_{j}\right)\right\rangle\right)$.

2. From here, apply Only n's Excess Claim Matters repeatedly to obtain $F_{2}(\omega)=$ $F_{2}\left(\left\langle\left\{1,2, D_{2}\right\},\left(e_{1}, e_{2}, 0\right),\left(c_{1}, c_{2}, \sum_{j \in D_{2}}\left(c_{j}-e_{j}\right)\right\rangle\right)\right.$.

3. From here, given that $F_{1}(\omega)=\min \left\{E_{1}, c_{1}\right\}$, apply Upstream Consistency to obtain $F_{2}(\omega)=F_{2}\left(\left\langle\left\{2, D_{2}\right\},\left(E_{2}, 0\right),\left(c_{2}, \sum_{j \in D_{2}}\left(c_{j}-e_{j}\right)\right\rangle\right)\right.$, with $E_{2}=e_{1}+e_{2}-F_{1}(\omega)=$ $e_{2}+\max \left\{0, e_{1}-c_{1}\right\}$.

4. From here, apply the No Contribution Property to obtain $F_{2}(\omega)=\min \left\{E_{2}, c_{2}\right\}$. 
By repeating this last sequence of four steps for agents $3, \ldots, n-1$, using recursive application of Upstream Consistency in step 2, we obtain the Harmon rule: $F_{i}(\omega)=\min \left\{E_{i}, c_{i}\right\}$ for all $i \in N$.

\section{Proof of Lemma 2}

Proof. Let $F$ be the No-harm rule such that $F_{i}(\omega)=\max \left\{0, E_{i}-c_{D_{i}}\right\}$ for all $i \in N$, and consider a river claims problem $\omega=\langle N, e, c\rangle$. We prove the lemma for each axiom separately.

River Composition Because the No-harm rule does not satisfy Composition Downstream (see below), it also does not satisfy the stronger River Composition.

Composition Downstream An example suffices to show that the No-harm rule does not satisfy Composition Downstream. Consider $\omega=\langle N, e, c\rangle$ with 3 agents, $e=(1,1,0)$, and $c=(2,2,2)$, and take $e^{\prime}=(1,1,1)$. The No-harm rule gives the solutions $F(\omega)=$ $(0,0,2), F\left(\omega^{\prime}\right)=(0,1,2)$, and $F\left(\omega^{\prime \prime}\right)=(0,0,0)$, the problem $\omega^{\prime \prime}$ being a river claims problem with downstream abundance but upstream scarcity. Clearly, $F\left(\omega^{\prime}\right)=(0,1,2) \neq(0,0,2)=$ $F(\omega)+F\left(\omega^{\prime \prime}\right)$.

Composition Upstream The No-harm rule allocates water as far downstream as possible. This implies for any problem $\omega$ that $F_{i}(\omega)>0$ only if $F_{i+1}(\omega)=c_{i+1}$. Therefore, the solution by the No-harm rule is of the form:

$$
F(\omega)=\left(0, \ldots, 0, F_{j}(\omega), c_{j+1}, \ldots, c_{n}\right),
$$

with $0<F_{j}(\omega) \leq c_{j}$ for some $j \in N$, subject to the minimum waste requirement in Definition 2. We proceed in three steps.

1. Consider some agent $i \in N$ such that $e=\left(0, \ldots, 0, e_{i+1}, \ldots, e_{n}\right)$ and consider the related problem $\omega^{\prime}=\left\langle N, e^{\prime}, c\right\rangle$ with $e^{\prime}=\left(e_{1}^{\prime}, \ldots, e_{i}^{\prime}, e_{i+1}, \ldots, e_{n}\right)$. By (1) we have $F\left(\omega^{\prime}\right)=\left(0, \ldots, 0, F_{j^{\prime}}\left(\omega^{\prime}\right), c_{j^{\prime}+1}, \ldots, c_{n}\right)$. Because $e^{\prime}>e$, we have $j^{\prime} \leq j$, with $F_{j^{\prime}}\left(\omega^{\prime}\right)>$ $F_{j}(\omega)$ in case of equality, so that $F_{i}\left(\omega^{\prime}\right) \geq F_{i}(\omega)$ for all $i \in N$.

2. Now, consider the related problem $\omega^{\prime \prime}=\left\langle N, e^{\prime}-e, c-F(\omega)\right\rangle$. By (1) and the result of Step 1 , we have $e^{\prime}-e=\left(e_{1}^{\prime}, \ldots, e_{i}^{\prime}, 0, \ldots, 0\right)$ and $c-F(\omega)=\left(c_{1}, \ldots, c_{j-1}, c_{j}-F_{j}(\omega), 0, \ldots, 0\right)$ with $j>i$. By (1) we have $F\left(\omega^{\prime \prime}\right)=\left(0, \ldots, 0, F_{j^{\prime \prime}}\left(\omega^{\prime \prime}\right), c_{j^{\prime \prime}+1}, \ldots, c_{j-1}, c_{j}-F_{j}\left(\omega^{\prime}\right), 0, \ldots, 0\right)$, such that $j^{\prime \prime} \leq j$. 
3. We have $F(\omega)+F\left(\omega^{\prime \prime}\right)=\left(0, \ldots, 0, F_{j^{\prime \prime}}\left(\omega^{\prime \prime}\right), c_{j^{\prime \prime}+1}, \ldots, c_{n}\right)$. Taking $j^{\prime \prime}=j^{\prime}$ we have $F\left(\omega^{\prime}\right)=F(\omega)+F\left(\omega^{\prime \prime}\right)$; the No-harm rule satisfies Composition Upstream.

River Path Independence Similar to the proof of Composition Upstream, we use the solution by the No-harm rule as given in (1). We proceed in two steps.

1. Consider the related problem $\omega^{\prime}=\left\langle N, e^{\prime}, c\right\rangle$ with $e^{\prime}<e$. By (1) we have $F\left(\omega^{\prime}\right)=$ $\left(0,0, \ldots, 0, F_{j^{\prime}}\left(\omega^{\prime}\right), c_{j^{\prime}+1}, \ldots, c_{n-1}, c_{n}\right)$. Because $e^{\prime}<e$, we have $j^{\prime} \geq j$, with $F_{j^{\prime}}\left(\omega^{\prime}\right)<$ $F_{j}(\omega)$ in case of equality, so that $F_{i}\left(\omega^{\prime}\right) \leq F_{i}(\omega)$ for all $i \in N$.

2. Now, consider the related problem $\omega^{\prime \prime}=\left\langle N, e^{\prime}, F(\omega)\right\rangle$. By (1), for a given endowment vector $e^{\prime}$, any problem with a claims vector that weakly dominates $F\left(\omega^{\prime}\right)$ leads to the solution $F\left(\omega^{\prime}\right)$. Since $F\left(\omega^{\prime}\right) \leq F(\omega)$ (the result of Step 1) and because $F(\omega)$ is the claims vector in problem $\omega^{\prime \prime}$-which has the same endowment vector $e^{\prime}$ as problem $\omega^{\prime}$-we have $F\left(\omega^{\prime}\right)=F\left(\omega^{\prime \prime}\right)$; the No-harm rule satisfies River Path Independence. 


\section{References}

Ambec, S., A. Dinar, and D. McKinney (2013). Water sharing agreements sustainable to reduced flows. Journal of Environmental Economics and Management 66(3), 639655.

Ambec, S. and L. Ehlers (2008). Sharing a river among satiable agents. Games and Economic Behavior 64(1), 35-50.

Ambec, S. and Y. Sprumont (2002). Sharing a river. Journal of Economic Theory 107(2), 453-462.

Ansink, E., M. Gengenbach, and H.-P. Weikard (2012). River sharing and water trade. FEEM Working Paper 017.2012.

Ansink, E. and H. Houba (2013). Sustainable agreements on stochastic river flow. Tinbergen Institute Discussion Paper 2013/182.

Ansink, E. and A. Ruijs (2008). Climate change and the stability of water allocation agreements. Environmental and Resource Economics 41(2), 249-266.

Ansink, E. and H.-P. Weikard (2009). Contested water rights. European Journal of Political Economy 25(2), 247-260.

Ansink, E. and H.-P. Weikard (2012). Sequential sharing rules for river sharing problems. Social Choice and Welfare 38(2), 187-210.

Arrow, K., P. Dasgupta, L. Goulder, G. Daily, P. Ehrlich, G. Heal, S. Levin, K.-G. Mäler, S. Schneider, D. Starrett, and B. Walker (2004). Are we consuming too much? Journal of Economic Perspectives 18(3), 147-172.

Bates, B., Z. Kundzewicz, S. Wu, and J. Palutikof (2008). Climate change and water. Intergovernmental Panel on Climate Change, Technical Paper VI.

Beach, H., J. Hammer, J. Hewitt, E. Kaufman, A. Kurki, J. Oppenheimer, and A. Wolf (2000). Transboundary Freshwater Dispute Resolution: Theory, Practice, and Annotated References. Tokyo: United Nations University Press.

Béal, S., A. Ghintran, E. Rémila, and P. Solal (2013). The river sharing problem: A survey. International Game Theory Review 15(3), 1340016. 
Béal, S., E. Rémila, and P. Solal (2012). The sequential equal surplus division for sharing a river. MPRA Paper No. 37346, Munich Personal RePEc Archive.

Chun, Y. (1988). The proportional solution for rights problems. Mathematical Social Sciences 15(3), 231-246.

Daoudy, M. (2008). Hydro-hegemony and international water law: Laying claims to water rights. Water Policy 10(S2), 89-102.

De Stefano, L., J. Duncan, S. Dinar, K. Stahl, K. Strzepek, and A. Wolf (2012). Climate change and the institutional resilience of international river basins. Journal of Peace Research 49(1), 193-209.

Demange, G. (2004). On group stability in hierarchies and networks. Journal of Political Economy 112(4), 754-778.

Dettinger, M. and H. Diaz (2000). Global characteristics of stream flow seasonality and variability. Journal of Hydrometeorology 1(4), 289-310.

Dinar, A. and G. Nigatu (2013). Distributional considerations of international water resources under externality: The case of Ethiopia, Sudan and Eypt on the Blue Nile. Water Resources and Economics 2-3, 1-16.

Dinar, A., A. Ratner, and D. Yaron (1992). Evaluating cooperative game theory in water resources. Theory and Decision 32(1), 1-20.

Herrero, C., M. Maschler, and A. Villar (1999). Individual rights and collective responsibility: The rights-egalitarian solution. Mathematical Social Sciences 37(1), 59-77.

Houba, H. (2008). Computing alternating offers and water prices in bilateral river basin management. International Game Theory Review 10(3), 257-278.

İlkılıç, R. (2011). Networks of common property resources. Economic Theory 47(1), $105-134$.

Khmelnitskaya, A. (2010). Values for rooted-tree and sink-tree digraph games and sharing a river. Theory and Decision 69(4), 657-669.

Kilgour, D. and A. Dinar (2001). Flexible water sharing within an international river basin. Environmental and Resource Economics 18(1), 43-60. 
Krzysztofowicz, R. (2001). The case for probabilistic forecasting in hydrology. Journal of Hydrology 249(1-4), 2-9.

McCaffrey, S. (2007). The Law of International Water Courses. Oxford: Oxford University Press.

Milly, P., K. Dunne, and A. Vecchia (2005). Global pattern of trends in streamflow and water availability in a changing climate. Nature 438(7066), 347-350.

Montanari, A. and G. Grossi (2008). Estimating the uncertainty of hydrological forecasts: A statistical approach. Water Resources Research 44(12), W00B08.

Moreno-Ternero, J. (2011). A coalitional procedure leading to a family of bankruptcy rules. Operations Research Letters 39(1), 1-3.

Moulin, H. (1987). Equal or proportional division of a surplus, and other methods. International Journal of Game Theory 16(3), 161-186.

Moulin, H. (2000). Priority rules and other asymmetric rationing methods. Econometrica 68(3), 643-684.

Olmstead, S. (2010). The economics of managing scarce water resources. Review of Environmental Economics and Policy 4(2), 179-198.

O'Neill, B. (1982). A problem of rights arbitration from the Talmud. Mathematical Social Sciences 2(4), 345-371.

Salman, S. (2007). The Helsinki Rules, the UN Watercourses Convention and the Berlin Rules: Perspectives on international water law. International Journal of Water Resources Development 23(4), 625-640.

Tanzeema, S. and I. Faisal (2001). Sharing the Ganges: A critical analysis of the water sharing treaties. Water Policy 3(1), 13-28.

Thomson, W. (2001). On the axiomatic method and its recent applications to game theory and resource allocation. Social Choice and Welfare 18(2), 327-386.

Thomson, W. (2003). Axiomatic and game-theoretic analysis of bankruptcy and taxation problems: A survey. Mathematical Social Sciences 45(3), 249-297.

Thomson, W. (2013). A characterization of a family of rules for the adjudication of conflicting claims. Games and Economic Behavior 82, 157-168. 
Van den Brink, R., A. Estévez-Fernández, G. van der Laan, and N. Moes (2011). Independence axioms for water allocation. Tinbergen Institute Discussion Paper 2011/128.

Van den Brink, R., A. Estévez-Fernández, G. van der Laan, and N. Moes (2013). Independence of downstream and upstream benefits in river water allocation problems. Forthcoming in Social Choice and Welfare.

Van den Brink, R., G. van der Laan, and N. Moes (2012). Fair agreements for sharing international rivers with multiple springs and externalities. Journal of Environmental Economics and Management 63(3), 388-403.

Van den Brink, R., G. van der Laan, and V. Vasil'ev (2007). Component efficient solutions in line-graph games with applications. Economic Theory 33(2), 349-364.

Ward, P., W. Beets, L. Bouwer, J. Aerts, and H. Renssen (2010). Sensitivity of river discharge to ENSO. Geophysical Research Letters 37(12), L12402.

Wolf, A. (1999). Criteria for equitable allocations: The heart of international water conflict. Natural Resources Forum 23(1), 3-30.

Young, P. (1988). Distributive justice in taxation. Journal of Economic Theory 43(2), $321-335$. 